\title{
Taxes to influence energy use in road transportation in Australia
}

\author{
Prafula Pearce* \\ Curtin Law School, Curtin University, Perth, Australia
}

Received: 28 February 2017 / Received in final form: 2 July 2017 / Accepted: 27 July 2017

\begin{abstract}
The desire to achieve a shift towards renewable energy will be difficult to achieve without a change in the energy use in road transportation in Australia. The transport sector in Australia is heavily reliant on oil and is responsible for contributing $18.1 \%$, of Australia's annual greenhouse gas emissions. This paper examines the current Australian tax policy and its inability to make an impact on transport choices that would reduce energy use and emissions and promote alternative energy use. Some of the current taxes such as the luxury car tax can be singled out as a tax that has passed its "use-by" date. The paper explores how the Australian Government can use targeted taxation measures in order to encourage the purchase of low energy consumption and low-emission vehicles, reduce the number of registered cars on Australian roads and control the use of cars as a means of personal transportation. A comprehensive tax measure suggested in this paper is the luxury energy tax based on the premise that energy use in transportation is a luxury and should be taxed appropriately in order to curb its use and bring about a behaviour change in the choice and usage of motor vehicles.
\end{abstract}

\section{Introduction}

The transport sector in Australia is heavily reliant on oil which is not only a non-renewable resource with limited supply, but is also responsible for $18.1 \%$ of Australia's greenhouse gas (GHG) emissions. The reliance on motor vehicles for passenger transportation has been made possible due to the cheap availability of oil. However, it is time to change as the Australian government reports indicate that Australia's oil resources are in decline as crude oil resources are being depleted at a faster rate than they are being replenished by discovery, and as a result, Australia is increasingly relying on imported oil. Since passenger vehicles in Australia consume the most oil, that is the focus of investigation of this research.

Adapting behaviour in order to reduce the demand for oil, and implement alternative energy sources in passenger motor vehicles takes time. History has demonstrated that humans are slow to change. If we examine American history and the abolition of the slave trade, the southern US states were plunged into a deep crisis and it took a century for the southern states to recover and catch up with the northern states. By comparison, developing alternative energy technologies for transportation and its uptake is likely to be even harder. It is likely that when oil becomes scarce, there may be slow and painful processes of social

\footnotetext{
* e-mail: Prafula.Pearce@curtin.edu.au
}

and technological adjustments that could last for a century or more. Countries that are likely to survive better are those that are prepared to change [1].

An examination of the Australian sector reveals that it is the second largest consumer of energy as shown in Table 1 and road transport is the largest energy consumer with $73.1 \%$ consumption [2].

There were 18.4 million registered motor vehicles in Australia as at 31 January 2016, of which passenger motor vehicles accounted for $75.1 \%$ of the vehicle fleet [3]. Fossil fuels dominate Australia's primary energy consumption in the transport sector, i.e. 95\% of energy used for all transport modes was crude oil derived liquid fuels with liquid petroleum gas being the most significant alternative fuel comprising only $2.7 \%$ [4]. In fact oil remains the largest primary energy consumption source and represents $37.8 \%$ of the total energy use, whereas coal only represents $32.2 \%$ of the total energy use.

The transport sector also accounts for 92.2 Mtonnes, or $18.1 \%$, of Australia's annual GHG emissions. Within the transport sector, $84.9 \%$ of GHG emissions can be attributed to road transport activities [5]. In 2014, the Climate Change Authority reported that transport emissions increased by $46 \%$ between 1990 and 2012 [6]. It is the responsibility of the Australian Government to be aware of the energy use in transportation that causes increased GHG emissions and also the negative transport externalities it causes such as congestion, safety and health, energy security and economic prosperity. 
Table 1. Australian energy consumption by industry in 2014-2015.

\begin{tabular}{llc}
\hline Industry sector & Energy consumption (PJ) & Percentage share \\
\hline Transport & 1612.9 & 27.2 \\
Electricity supply & 1666.9 & 28.2 \\
Manufacturing & 1147.1 & 19.4 \\
Others including: residential; commercial; agriculture; construction & 1492.7 & 25.2 \\
Total & & 100 \\
\hline
\end{tabular}

Source: Department of Industry, Innovation and Science, Australian Energy Statistics, 2016.

In Australia, passenger vehicles dominate personal road transportation, passenger motor vehicles used for personal transportation are considered expensive in terms of energy use. Buses and trains are far more energy efficient than a personal passenger motor vehicle. Newman and Kenworthy note that a fully loaded electric train is five times more energy efficient than a car ([7], p. 85). Even the weight allocation per passenger of a personal passenger motor vehicle can be far greater than for a train, bus or even an aeroplane. Compared with aeroplanes, trains or buses where the weight allocation per passenger is $300-350 \mathrm{~kg}$, motor vehicles weighing between 1000 and $2500 \mathrm{~kg}$ are often used by one or two passengers at a time on a journey. The Airbus A340-600 aircraft has an operating empty weight of $130200 \mathrm{~kg}$ and can carry between 295 and 440 passengers, resulting in a weight allocation per passenger of between 295 and $441 \mathrm{~kg}$ [8]. Transperth "A series" two-car trains weigh $94000 \mathrm{~kg}$ and each car has the capacity to carry 72 seated and 82 standing passengers. This results in a weight allocation of $305 \mathrm{~kg}$ per passenger. A natural gas bus weighs $18000 \mathrm{~kg}$ and is licensed to carry 59 passengers, resulting in an allocation of $305 \mathrm{~kg}$ per passenger. In order to obtain an average of $300 \mathrm{~kg}$ per passenger for a passenger motor vehicle that carries four passengers, the motor vehicle should not weigh more than $1200 \mathrm{~kg}$. However, only small cars such as the Honda Civic 2016 and Hyundai i30 weighs about $1200 \mathrm{~kg}$ whereas the SUV's that are now in greater demand can weigh in excess of $2000 \mathrm{~kg}$. The question is whether we need two tonnes or more of metal in a passenger motor vehicle to carry a few hundred kilograms of passenger body weight.

In order to reduce the use of energy in passenger motor vehicles, it is necessary to shift the focus from motor vehicles being a symbol of financial success and social status to being simply a means of transportation. The basic question to address is whether we as a society can afford to waste energy, especially the precious energy resource by allowing passenger motor vehicles weighing $2000 \mathrm{~kg}$ or more to carry between 100 and $400 \mathrm{~kg}$ of passenger weight. The question to also ask is whether Australians who drive energy-guzzling motor vehicles for personal transportation know the impact of their choice on the depletion of oil and the future ramifications. An effective way to educate Australians about choosing suitable motor vehicles for personal transportation is through an appropriate motor vehicle taxation policy. The Australian Institute of Engineers recommended in their report on sustainable transport that taxation and fiscal policy instruments should encourage sustainable transport ([7], p. 88). A Discussion Paper in October 2010 by Consult Australia on Transporting Australia's Future supports the recommendations from the Henry Tax Review and the COAG Road Reform Plan towards mass-distance-location-based charging for road use and this would require coordination across all levels of government [9]. A discussion paper produced by Deloitte for Infrastructure Partnership Australia state that the Australian Government should review the road pricing system and recommended that a Universal Road User Charging Model should be adopted that considers the following user behaviour: mass of the vehicle; the energy consumed; the road location; and the time of the road use, i.e. peak period or not [10].

The Climate Change Authority Targets and Progress Review has specified three broad ways to reduce transport emissions: gradually change the motor vehicle fleet to reduce the amount of carbon-containing fuel to transport people and freight; switch from use of conventional fuels with lower emission alternative fuels such as electricity, natural gas and sustainable biofuels; and change the way people and freight are moved [11].

This paper submits that there is a need for a tax that will promote a change in driver behaviour towards choosing lighter and less powerful vehicles for passenger transportation, thereby reducing emissions and reducing dependence on energy, especially oil. A specific motor vehicle tax framework to reduce the consumption of oil and promote alternative energy use may be an option under the pigovian tax principles [12].

The research undertaken as part of this author's Ph.D. was to examine the realistic tax measures that can be implemented and the criteria that the design of tax framework should take into account to reform the choice and usage of motor vehicles for personal transportation in Australia in order to reduce the consumption of energy, especially oil and also reduce transport emissions [13]. Most consumers only change their behaviour when there is a financial incentive to do so.

\section{Methodology}

The methodology used to answer the research question was Interpretive Description. Interpretive description is an articulation of a qualitative approach to description with an interpretive or explanatory flavour. It offers the 
potential to deconstruct the angle of vision upon which prior knowledge has been erected to generate new insights that shape new inquiries and applications. Thorne states that in interpretive description, findings reflect an interpretive manoeuvre within which the researcher considers what the pieces might mean, individually and in relation to one another, including the sequence of presentation that the researcher uses that leads the eventual reader toward a kind of knowing that was not possible prior to the study ([14], p. 35). The new organised structures in themselves may not advance knowledge. However, when the organising structures are given subjective interpretation and experience and they reveal new possibilities in the relationship between subjective experience and conceptual knowledge, then they will have achieved their essential purpose ([14], p. 175).

The research discussed in this paper offers the potential for deconstructing prior knowledge in three areas, these being the status of oil reserves as this is the energy source used mainly for transportation; the characteristics of motor vehicles that impact upon the consumption of energy; and the tax and regulatory measures which may be adopted by Australia to influence the choice of passenger motor vehicles. These three areas when viewed independently do not create new knowledge. However, putting the knowledge in these areas together gives rise to a new inquiry and a need to investigate a solution through tax and regulatory reform.

\section{Results and discussion}

The first reality is that the oil resource is finite and oil is a nonrenewable source of energy. Moreover, Australia has a limited supply of oil and is therefore dependent on foreign oil. Also, an examination of the current motor vehicle taxes in Australia, being goods and services tax (GST) and luxury car tax (LCT) on purchase of a vehicle, excise duties and motor vehicle license fees on use of the vehicle reveal that they do not discourage the common attributes that cause excessive oil or energy usage in a passenger motor vehicle.

The GST at the standard rate of $10 \%$ of the cost of vehicle has no bearing on the energy consumption of the vehicle. The LCT was introduced in Australia on 1 July 2000 as part of the Tax Reform Plan to introduce GST. The LCT only serves a historical purpose. The originally high wholesale sales tax on luxury cars was imposed in order to protect the Australian car manufacturing market and act as a tariff on imported cars. However, local car manufacturing will be finished by 2018 and the Australian Government has announced changes to the Motor Vehicle Standards Act that will permit the importation of a personal motor vehicle that has less than $500 \mathrm{~km}$ on the odometer and is less than 12 months old. The LCT is discriminatory as other luxury items such as jewellery, yachts, holiday homes, etc., do not attract any extra taxation. As regards annual motor vehicle license fees, this is a State tax and each State uses a different method to calculate the fees.

The states in Australia impose taxes on vehicle purchase, transfer of ownership and annual motor vehicle registration fees, and these taxes vary from state to state, for example, New South Wales and Western Australian annual registration charges are based on weight, South Australian charges depend on the number of cylinders and the Northern Territory and Victorian charges are based on the engine size - these taxes have a very low impact on a person's choice of passenger motor vehicle. Furthermore, these taxes are not imposed at the time of making a vehicle purchase. The Commonwealth government in Australia does impose the LCT at the time the vehicle is purchased, but the tax is based on the purchase price and not the characteristics of the motor vehicle that cause excessive oil or energy use or emissions. Also, the current fuel excise imposed by the Commonwealth Government at a flat rate per litre of fuel is not sufficiently high to influence motorists' choice and usage of passenger motor vehicles and should be part of the comprehensive motor vehicle tax reform.

The proposal to reform Australia's motor vehicle taxes is in line with recommendations made by the Henry Tax Review, which noted that the existing road transport taxes in Australia are not appropriate to meet Australia's future transport challenges, and that transport taxes should be designed to correct market failures in the transport sector [15]. In this respect, this paper highlights that priority should be given to energy usage in passenger motor vehicles and this could be best achieved if there was a harmonious relationship between the Australian energy, transportation and tax policies in order to promote the choice of passenger vehicles that consume less fuel or use cleaner fuels, encourage a reduction in the use of vehicles, and lead to a reduction in congestion. Instead of having a variety of taxes with no specific objectives other than raising revenue, a comprehensive tax on motor vehicles should be introduced that targets the attributes of a motor vehicle that cause excessive energy use.

By carrying out an orderly reform of passenger motor vehicle taxes, the government of Australia can educate its people to seek motor vehicles that consume less energy as energy should be considered a luxury and the use of that luxury should be taxed. Thus, as part of this research, the design criteria of a comprehensive motor vehicle taxation system called luxury energy tax (LET) were investigated.

The investigation revealed that the framework of the LET system should reflect the common attributes of a motor vehicle that cause excessive energy usage. These were found to be:

- the weight of the vehicle;

- the size of the engine or engine capacity;

- the engine power.

In addition, it was noted that the LET should also reflect the $\mathrm{CO}_{2}$ emissions.

\subsection{The vehicle weight}

It was noted that the vehicle weight influences the energy required to move the vehicle in order to overcome the force of inertia, overcome air drag and tyre friction and a heavier car would require more energy to move [16]. Research undertaken by Cheah indicates that fuel consumption is reduced by $5-7 \%$ for every $10 \%$ reduction 
Table 2. Calculation of points to determine luxury energy taxable value.

\begin{tabular}{|c|c|c|c|c|}
\hline Points & Weight (kg) & Capacity (cc) & Power $(\mathrm{kW})$ & $\mathrm{CO}_{2}$ emissions $(\mathrm{g} / \mathrm{km})$ \\
\hline 0 & 600 & 600 & 40 & 80 \\
\hline 1 & 680 & 780 & 50 & 88 \\
\hline 2 & 760 & 960 & 60 & 96 \\
\hline 3 & 840 & 1140 & 70 & 104 \\
\hline 4 & 920 & 1320 & 80 & 112 \\
\hline 5 & 1000 & 1500 & 90 & 120 \\
\hline 6 & 1080 & 1680 & 100 & 128 \\
\hline 7 & 1160 & 1860 & 110 & 136 \\
\hline 8 & 1240 & 2040 & 120 & 144 \\
\hline 9 & 1320 & 2220 & 130 & 152 \\
\hline 10 & 1400 & 2400 & 140 & 160 \\
\hline 11 & 1480 & 2580 & 150 & 168 \\
\hline 12 & 1560 & 2760 & 160 & 176 \\
\hline 13 & 1640 & 2940 & 170 & 184 \\
\hline 14 & 1720 & 3120 & 180 & 192 \\
\hline 15 & 1800 & 3300 & 190 & 200 \\
\hline 16 & 1880 & 3480 & 200 & 208 \\
\hline 17 & 1960 & 3660 & 210 & 216 \\
\hline 18 & 2040 & 3840 & 220 & 224 \\
\hline 19 & 2120 & 4020 & 230 & 232 \\
\hline 20 & 2200 & 4200 & 240 & 240 \\
\hline 21 & 2280 & 4380 & 250 & 248 \\
\hline 22 & 2360 & 4560 & 260 & 256 \\
\hline 23 & 2440 & 4740 & 270 & 264 \\
\hline 24 & 2520 & 4920 & 280 & 272 \\
\hline 25 & 2600 & 5100 & 290 & 280 \\
\hline 26 & 2680 & 5280 & 300 & 288 \\
\hline 27 & 2760 & 5460 & 310 & 296 \\
\hline 28 & 2840 & 5640 & 320 & 304 \\
\hline 29 & 2920 & 5820 & 330 & 312 \\
\hline 30 & 3000 & 6000 & 340 & 320 \\
\hline
\end{tabular}

in vehicle weight. Cheah also states that reductions in vehicle weight can be achieved by replacing heavy materials with lighter materials such as high-strength steel, aluminium or magnesium, and by vehicle redesign and vehicle downsizing. She states that creative redesign can be employed by motor vehicle manufacturers to reduce vehicle size and weight whilst maintaining the same interior space. Another way of reducing weight is to consolidate, eliminate or downsize parts or remove some optional content from the motor vehicle [17]. In Australia, not only has the weight of a vehicle increased over the years, but the percentage demand for new SUV's has been increasing compared with the demand for new passenger cars that has been on the decline. By recognising the vehicle weight as one of the characteristics in the design of the LET, users will have a choice between purchasing and using lighter motor vehicles or paying the tax.

\subsection{The size of the engine or engine capacity}

Engines with greater capacities are usually more powerful and provide greater torque at lower revolutions per minute. Motor vehicle manufacturers often use a large engine capacity as a marketing point to sell more vehicles, in that a model with a larger engine capacity is more powerful and has the capacity to reduce time at take-off when accelerating from zero to $100 \mathrm{~km} / \mathrm{h}$. A bigger engine will also weigh more, creating more rolling resistance. Therefore an engine that is larger in cubic centimetres has the capacity to increase power and in the process consume more energy. The design of the LET should penalise the engine capacity on an incremental basis. Plotkin states that a small engine that uses its substantial power most of the time with a facility to artificially boost its power when required is better than a large engine that only uses its substantial power on take-off [16]. 
Table 3. Taxing points converted to luxury energy tax.

Imposition of tax

Initial new purchase of vehicle

Annual road registration

Fuel consumption per litre

Disposal fee
Tax payable per point

AUD500 per point

AUD125 per point

AUD0.25 per point

AUD10 per point

\subsection{The engine power}

The design of the LET should also take into consideration the power generated by a motor vehicle since engine weight, engine capacity and engine power are interrelated and if one of the factors is omitted from a tax scheme, it can encourage policy gaming. A smaller motor vehicle engine can be made to produce more power in a number of ways such as forced air induction.

Imposing a LET on the engine power would encourage consumers to seek motor vehicles with engines that do not produce excessive power, and such motor vehicles may drive a little slower, resulting in reduced air drag. Air drag varies according to the speed of the car; increase the speed, square the amount of air drag. Thus reducing the speed of the motor vehicle can reduce drag, and since greater drag requires more energy to overcome it, reducing the drag means a reduction in energy consumption. Modern engines can have higher compression ratios which minimises the need for a substantial amount of boost to make reasonable power.

\section{4 $\mathrm{CO}_{2}$ emissions}

In addition to the three characteristics of weight, engine capacity and engine power, the LET should also discourage passenger motor vehicles with high $\mathrm{CO}_{2}$ emissions. A study undertaken in 2002 by the European Commission's Directorate-General for Environment on fiscal measures to reduce $\mathrm{CO}_{2}$ emissions in new passenger cars concluded that a $\mathrm{CO}_{2}$ component in car taxation systems with significantly progressive tax rates could provide a solid incentive for consumers to choose a car with low $\mathrm{CO}_{2}$ emissions. The report concluded that the more progressive the curve, the larger its effects would be [18].

\subsection{The taxing points}

The LET system in Australia should encompass the four characteristics of the motor vehicle, being its weight, engine capacity, engine power and $\mathrm{CO}_{2}$ emissions, and to make the system comprehensive, the same characteristics should be taxed at four taxing points being:

- the purchase of the vehicle;

- the annual registration;

- the fuelling of the vehicle;

- the disposal of the vehicle.

Including the same motor vehicle characteristics at each of the proposed taxing points makes the LET system comprehensive, and the impact of purchasing a particular motor vehicle is reflected throughout the ownership of the vehicle.
The new purchase LET has the potential to be quite high depending on the four characteristics of the chosen vehicle and the tax rate. The LET payable on the purchase of a new motor vehicle would differ for each vehicle as the four characteristics would differ for each vehicle. Therefore the purchase LET is likely to make an impact on the choice of the vehicle and the characteristics that impact on the use of energy or oil in a passenger motor vehicle.

It is proposed that the calculation of the annual registration LET would be based on the same four motor vehicle characteristics that were reflected in the purchase LET, i.e. the vehicle weight, engine capacity, engine power and $\mathrm{CO}_{2}$ emissions. The reason for this is to allow the proposed LET design to influence not only the purchasing decision, but to have that decision reflected right throughout the ownership of the vehicle, including the annual registration charges, as well as the fuelling of the vehicles. The cost of the fuel for each motor vehicle should also include the same four motor vehicle characteristics since energy is considered a luxury, and a person who chooses to drive a motor vehicle that has the potential to use more energy should have to pay for fuel at a higher rate, the aim being to deter motorists from choosing such motor vehicles.

The reason for including the disposal of the vehicle as a taxing point under the LET is to extend the consideration of motor vehicle characteristics to the point of disposal and the energy required for that disposal. A disposal fee would promote car designs that both attract lower disposal fees and have a longer existence.

Motor cars should be built to last for a reasonable time. Buses last for at least 20 years. Even aircraft used on long flights have a lifespan of at least 20 years or longer; some 747s last 25-30years. If aircraft that are exposed to extreme weather conditions are built to last at least 20 years, the question to ask is whether we are being extravagant in terms of energy usage by scrapping motor vehicles within 10 years. If motor vehicles were built to last, manufacturers might be inclined to use more expensive, energy-efficient materials in building the vehicle, for example, aluminium chassis and composite bodies. Thus the cost of the vehicle would not increase over its lifespan.

\subsection{The working design of LET}

The comprehensive LET design structure involves an allocation of points for each of the four motor vehicle characteristics. The points can be progressive, as demonstrated in Table 2, which displays 30 progressive points for each of the characteristics. 
The tax rate can then set for the LET points at each taxing point, as demonstrated in Table 3 . Discounts can be given to encourage a shift to alternative fuels.

The owner of each vehicle would need to be registered for LET and the LET points for the vehicle would be determined and transcribed on the vehicle number plate. This would make it possible to collect the taxes as four taxing points based on the allocated LET points. The fuelling station would be required to install a special number plate recognition technology system in order to impose the fuel LET on the vehicle being fuelled.

\section{Conclusion}

We as a society have a strong affinity to motor vehicles and we are increasingly dependent on oil. In this context, seeking behaviour change to shift to renewable energy by the use of persuasive methods is unlikely to succeed in bringing about a lasting change, and therefore regulatory and fiscal reforms are required. These reforms could also provide the opportunity to redesign and modernise the Australian public transport infrastructure. Many changes can be made, for example, if micro-light cars are encouraged for local area travel, then public transport should be encouraged for medium to long-distance travel.

The Australian government should take the responsibility to implement appropriate taxation policies such as the proposed LET, in order to promote the efficient movement of people and goods with the least consumption of energy from oil and promote a shift to renewable energy.

\section{References}

1. J. Friedrichs, Global energy crunch: how different parts of the world would react to a peak oil scenario, Energy Policy 38, 4562 (2010)

2. Australian Government, Department of Industry, Innovation and Science, Australian Energy Update (2016)

3. Australian Bureau of Statistics, Motor Vehicle Census (2016)
4. Commonwealth of Australia, Rural and Regional Affairs and Transport References Committee, Australia's Transport Energy Resilience and Sustainability (2015), pp. 3-4

5. Commonwealth of Australia, Australian National Greenhouse Accounts: National Inventory Report, The Australian Government Submission to the United Nations Framework Convention on Climate Change (2015), Vol. 1, p. 40

6. Commonwealth of Australia, Australia's Sixth National Communication on Climate Change (2013), pp. 86-88

7. P. Laird et al., in Back on Track: Rethinking Transport Policy in Australia and New Zealand (University of New South Wales Press, Australia, 2001), pp. 85 and 88

8. Airbus, A340-600 Global Performer (2017)

9. Consult Australia, Transporting Australia's Future (2010)

10. Infrastructure Partnership Australia, Road Pricing and Transport Infrastructure Funding: Reform Pathways for Australia (2013)

11. Australian Government Climate Change Authority, Reducing Australia's Greenhouse Gas Emissions - Targets and Progress Review Final Report, 2014, p. 163

12. J. Freebairn, Environmental taxation and its possible application in Australia, in Proceedings of Australia's Future Tax Policy Conference (2009)

13. P. Pearce, in Using Tax and Regulatory Measures to Reform Choice and Usage of Motor Vehicles for Personal Transportation in Australia for the Sustainability of Oil (Australian Tax Research Foundation, Research Study 48, 2013)

14. S. Thorne, in Interpretive Description (Left Coast Press, California, 2008), pp. 35 and 175

15. Commonwealth of Australia, Australia's Future Tax System: Final Report, 2010

16. S.E. Plotkin, Examining fuel economy and carbon standards for light vehicles, Discussion Paper No. 2007-1 Prepared for the International Transport Forum on the Cost and Effectiveness of Policies to Reduce Vehicle Emissions (OECD, 2007, p. 39)

17. L.W. Cheah, Cars on a Diet: The Material and Energy Impacts of Passenger Vehicle Weight Reduction in the US, Thesis, Doctor of Philosophy in Engineering Systems, Massachusetts Institute of Technology, 2010, p. 32

18. European Commission's Directorate-General for Environment, Fiscal Measures to Reduce $\mathrm{CO}_{2}$ Emissions from New Passenger Cars: Main Report, 2002, p. 114

Cite this article as: Prafula Pearce, Taxes to influence energy use in road transportation in Australia, Renew. Energy Environ. Sustain. 2, $16(2017)$ 